\title{
The disclosure in the Anti-Corruption Plans. Formal vs substantive attempts in the Italian Regional Governments
}

\author{
Clelia Fiondella*, Luca Ferri, Marco Maffei, Rosanna Spanò ${ }^{* *}$
}

Ricevuto il 7 marzo 2019

Accettato il 7 novembre 2019

\begin{abstract}
The current paper focuses on the disclosure divulged by Italian Regions in their Anticorruption Plans. It draws from the literature on the legitimacy theory to understand whether the information provided is driven by symbolic legitimacy purposes to pursue formal compliance or by substantive attempts to secure greater levels of accountability. To this aim, the study employs a meaning-oriented content analysis and a multiple correspondence analysis to assess the degree of thoroughness and the heterogeneity of the information, also identifying possible factors explaining any differences. The findings offer interesting implications for theory, practitioners, and policy makers.
\end{abstract}

Keywords: Corruption, Disclosure, Regulation, Italy, Legitimacy.

\section{Introduction}

Nowadays a number of factors is increasingly making government procurement a key site for corruption (Hawkins et al., 2011; Søreide, 2002; Rose-Ackerman, 1999). These factors encompass the magnitude and volume of procurement activities, ambiguity regarding the market value of many of the items being purchased, room for political discretion that characterises a huge number of government actors, and interdependence among political,

\footnotetext{
*Department of Economics, University of Campania, E-Mail: clelia.fiondella@unicampania.it.

** Department of Economics, Management, Institutions of the University of Naples Federico II -E-mail: luca.ferri@unina.it - marco.maffei@unina.it - rosanna.spano@unina.it.
}

Management Control (ISSN 2239-0391, ISSNe 2239-4397), 2019, 3

DOI: 10.3280/MACO2019-003008 
bureaucratic, and business players. The co-existence of complex relationships among these conditions puts forth a renewed attention for the promotion of accountability and transparency, which has led to extensive reforms in the fight against corruption, understood as dysfunction of public administration that emerges in the presence of monopoly and discretion (Hinna and Marcantoni, 2013).

Regulators and policy makers worldwide have undertaken a number of actions to prevent and detect corruption. These actions refer to improvements in internal controls and monitoring practices (cf., Strombom, 1998; Fearon, 2009), attention for the division of duties, the inclusion of procurement purchasing rules, policy manuals, and ethical guidelines. These have been recognised as crucial tools in limiting opportunities for corruption and to promote a change in organisational culture (Ongaro and Valotti, 2008; Benavides, 2006, p. 471; Anessi-Pessina and Steccolini, 2005; McCampbell and Rood, 1997). Moreover, emphasis has been placed on the essential need to foster the introduction of control tools and to ensure compliance with regulation, both at organisational and governmental levels (Siame, 2002; Gilman and Stout, 2008; Shim and Eom, 2008; Pavan and Fadda, 2013; Pavan et al., 2013).

The ever-expanding regulation to prevent corruption calls for reports disclosing mandatory information on the strategies and tools employed to prevent and detect the risk of corruption. These reports could be regarded as means of truly carrying out accountability, and to engender trust between governments and stakeholders. However, literature warns that it is likely that disclosure could be divulged for formal compliance purposes to the detriment of useful information capable to serve the above-cited wishes.

From this perspective, the current study falls into the domain of studies addressing performance management and measurement issues in public sector, especially looking at corruption prevention dynamics and the related accountability pressures. Acknowledging the nature of the topic explored in the current paper the theoretical perspective adopted as a reference is that of the Legitimacy theory. This framework likewise the stakeholder theory, has developed from the political economy perspective (Gray et al., 1996; Deegan, 2002). Both theories look at the nexus between the organisation and its operating environment (Neu et al., 2013). However, given that legitimacy theory exceeds the micro-level allowing us to accommodate notions of power relationships and discourses at a global level (Moerman and Van Der Laan, 2005) it is better fitted to the focus of the current study. 
Thus, the paper draws from the debate on the legitimacy theory to tap into the disclosure practices of Italian Regions in their Anti-corruption plans and aims to answer the following research question:

What are the main drivers of the disclosure provided by Italian Regions in their Anti-corruption Plans? What are the factors explaining any difference?

Consequently, the aim of the paper is to understand whether the information provided is driven by symbolic legitimacy purposes to pursue formal compliance or by substantive attempts to secure greater levels of accountability.

The paper focuses on the Italian setting for a threefold reason. First, the Word Bank has recently identified the country among those with the highest level of corruption in Europe, and the Global Corruption Barometer (Transparency International, 2013) indicates Italian Regional Governments and Local Entities as possible sites for high corruption in the perception of the citizens. Second, the country since 1992 (Del Monte and Papagni, 2007; Stolfi, 2008; Fiorino and Galli, 2013) has been very proactive to improve its regulation for the fight against corruption (Franchino and Radaelli, 2011). Third, Italy has adapted the national legal framework against corruption in the public sector with the promulgation of law decree 190/2012 and law 69/2015, also promulgating in 2013 the first National Anti-Corruption Plan (NAP), which requires Public Administrations to publicly report the initiatives taken to mitigate the corruption risk (Lisciandra and Millemaci, 2016; Fadda and Paglietti, 2016).

Moreover, the choice to identify Italian Regions as the point of reference for the analysis is related to the willingness to pay proper attention to issues relating to contextual and cultural features surrounding any policy implications. The focus on regions allows us to comprehend if there are any similarities between their disclosure practices and what are the factors that possibly influence any differences.

More specifically, to the aim of the study, the 20 Italian Regional Anticorruption Plans have been analysed by employing a meaning-oriented content analysis and a multiple correspondence analysis (MCA). Following extant approaches (Caldarelli et al., 2012; Caldarelli et al., 2013; Allini et al., 2019; Day and Woodward, 2004), the analysis is carried out in order to detect the degree of compliance with the NAP and the characteristics of the information in terms of thoroughness and heterogeneity of the reports.

The paper is organised as follows. The second section addresses the issues relating to public sector accountability and legitimacy issues with a fo- 
cus on the Italian policy for corruption prevention. The third section describes the research design. The fourth section reports the findings. The last section discusses the results and provides concluding remarks.

\section{Literature review and hypotheses development}

The ever-expanding attention for accountability in public sector has led to the compulsive adoption of variously conceived systems to monitoring and evaluating performance, often in the search for an objective "measurement culture". The danger is that reporting mainly based on "objective" indicators is likely to be somewhat redundant and extremely flawed, not useful to gain a better understanding of the phenomena investigated and, instead, able to create confusion rather than clarity. The recipients of information may find it difficult to consider the explanations obtained, or worse, may give way to measures of various kinds not substantially supported, and with possible negative effects (Morris et al., 2005; Pollit, 2006). In contrast, accountability trough reporting is achieved only when a holistic process of change is triggered.

In this regard, a number of studies has adopted the perspective of the Legitimacy Theory to focus on the role of information and disclosure in the relationship(s) between organisations, the State, individuals, and groups (Gray et al., 1996).

Legitimacy theory is grounded on the idea that there is a social contract between the organisation and the society in which it operates. Such a contract implies explicit and implicit expectations of the society in relation to organisation's activities and, in turn, fosters organisations to constantly seek to ensure that other parties perceive them as legitimate, i.e. that they are operating within the bounds and norms of their societies of reference (Suchman, 1995). Legitimacy - indented as the generalised perception that the actions of an entity are desirable, proper or appropriate within some socially constructed system of norms, values, beliefs and definitions (Suchman, 1995) is a relative concept and is time and place specific.

A primary aspect of this theoretical approach is that disclosure policies are regarded as a means to constitute a strategy to influence the organisation's relationships with other parties (Cho e Patten, 2007; Deegan et al., 2002). Usually disclosure-related strategies have been employed by companies to regain legitimacy after some legitimacy-threatening events, independently from the industry of reference. Such legitimation strategies are relevant also to gain and maintain legitimacy (Suchman, 1995; O’Donovan, 
2002). Public disclosure can be then used by organisations to counter or offset negative news that is publicly available, to provide material to inform interested parties about previously unknown aspects of the business activities, to draw attention on the organisation's strengths, and to down-play information concerning negative implications of the activities (Lindblom, 1994; Dowling and Pfeffer, 1975).

Some studies demonstrate that the extent and content of disclosure may vary as a consequence of changing society's expectations (Hogner, 1982). Other works maintain that an increase in the amount of "positive" disclosure is detectable in the periods following to negative events (Deegan and Rankin, 1997; Deegan et al., 2002). Yet other researches, demonstrated a positive correlation between media/social attention for certain issues, and the amount of disclosure divulged by companies (Deegan et al., 2002; Brown and Deegan, 1998). A dangerous aspect is that disclosure can be interpreted as a mere legitimation device and not as an accountability mechanism (Gray and Bebbington, 2000).

Thus, to fully understand if disclosure is aimed at reaching mere legitimation rather than at answering greater accountability demands, a possible way is to ascertain if this is employed as a symbolic or as a substantive technique.

Symbolic techniques do not reflect any real change in activities, while substantive techniques involve real material change in organisational goals, structures and processes, or socially institutionalized practices (Ashforth and Gibbs, 1990). This perspective is valuable to interpret recent trends in mandatory disclosure that over the last years have been progressively developed to satisfy increasing accountability demands in relation to corruption prevention.

Corruption prevention provisions are becoming increasingly crucial given that government procurement represents a key site for corruption due to monopoly and discretion (Hawkins et al., 2011; Del Monte and Papagni, 2007; Søreide, 2002). Contrasting this phenomenon is a policy priority for the development of communities and to achieve accountability demands (Kartall, 2014). Thus, the role of internal controls and monitoring practices (Fearon, 2009), the division of duties, procurement purchasing rules, the dissemination of policy manuals, and ethical guidelines (Benavides, 2006, p. 471) are nowadays essential domains of attention. Emphasis has been placed on the need to ensure compliance with control tools and regulation, both at organisational and government levels (Siame, 2002; Gilman and Stout, 2008; Magtulis and Poquiz, 2016), in order to satisfy the call for greater accountability in the public sphere. 
The picture described above is even more relevant for Italy because this setting is critical due to the high level of corruption perceived by citizens and economic operators. The Corruption Control Index developed by the World Bank places Italy among the last places in Europe and shows a negative trend. The Global Corruption Barometer found that among the most corrupt institutions, Italians indicate the political parties (69\%), the Parliament (44\%), public administration (29\%) and the health care system (24\%) and that only $56 \%$ of Italians would be willing to report cases of corruption. Moreover, corruption phenomena are facilitated in Italy by factors such as institutional decentralisation, established practices by governments to require the provision of certain services to third parties (individuals, cooperatives, corporations, etc.), the constant use of derogatory systems in the field of public procurement, and the persistence of personal appointment mechanisms instead of comparative evaluations. For these reasons, it is widely accepted that an effective fight against corruption represents a priority for Italy. It requires an integrated policy aimed at strengthening repressive remedies, and simultaneously introducing prevention tools.

Regulation to prevent corruption requires reports disclosing mandatory information on the strategies and tools employed to prevent and detect the risk of corruption. The regulation promulgated in Italy in 2012 obliges Public Institutions to adopt a preventive and innovative approach, not limited to the aspects of criminal repression (contemplated through the introduction of new hypotheses of crime as the "illicit traffic of influences" and the "corruption between privates"), but also aimed at reorganizing the government in terms of prevention and transparency.

Law no. 190/2012 and the National Anti-Corruption Plan (NAP) issued in 2013, mandate that Public Administrations, such as Regions, have to publicly report the initiatives taken to mitigate the corruption risk. Despite the positive judgment for the initiatives undertaken to date, several doubts still remain as to whether the reports provided by Regions are truly capable to satisfy the (substantive) information needs that led to their adoption, as well as to achieve substantive legitimacy purposes, instead of pursuing mere formal compliance objectives.

An essential element to ensure the usefulness of the reports towards greater accountability is that the preventive action reported about profoundly permeates the organisation and is based on a number of well-coordinated tools and processes. Furthermore, another potential and controversial problem may arise in relation to the possible risk of misalignment among Regions, which could derive from merely formal compliance efforts rather than from real differences in terms of cultural and contextual features, which is 
likely to compromise the usefulness of the disclosure and the comparability at the national level.

Consequently, this study verifies whether Regional Governments have provided only formal information in their Anti-Corruption Plans - merely for symbolic legitimacy purposes - or whether they have divulged a thorough disclosure substantially in line with the above-mentioned information and accountability needs.

We contend here that disclosure initiatives might be viewed as an attempt to inform citizens, enhance support of the political system, and increase participation in political actions, especially in areas featured by an high perception of corruption.

In this regard, it is worth noting that literature signals that corruption reduces the degree of economic growth representing an important obstacle to socio-economic development. Also, prior studies suggest the existence of several variables potentially able to influence corruption, and the content of corruption-related reporting (Edkins, 2009; Elzahar and Hussainey, 2012).

More specifically, many authors contend that the countries with a higher perception in respect to corruption and concussion are likely to have a lower GDP per capita (Sevuktekin et al., 2010). Other studies maintain that the perception of corruption and concussion decreases when there is a greater number of inhabitants because the corruption costs are splitted on more people (Sevuktekin et al., 2010). D'Onza et al. (2015; 2016) employed the above-cited variables, amongst others, to identify the determinants of the quantity of risk disclosure focusing on specific sections of the anticorruption plans of a sample of Italian Public administrations. They found a positive relation between the quantity of disclosure on the anticorruption measures, and both the size of the local authority considered and the degree of corruption in the territory. On these bases, and devoting attention to the thoroughness of disclosure for the reasons explained above, we advance the following hypotheses:

H1: there is a positive association between the degree of thoroughness of the disclosure and the regional dimension.

H2: there is a positive association between the degree of thoroughness of the disclosure and the regional degree of corruption and concussion.

At this stage, differently from D'Onza et al. (2015; 2016), we go beyond the counting issues to capture the degree of thoroughness of the information and to understand what are the legitimacy aspirations, we have to consider 
several additional elements. We already discussed that public disclosure can be used to draw attention on the organisation's strengths, and to down-play information concerning negative implications of the activities (Lindblom, 1994; Dowling and Pfeffer, 1975). Thus, the extent and content of disclosure may vary as a consequence of changing society's expectations (Hogner, 1982; Deegan and Rankin, 1997; Deegan et al., 2002). Clearly, such varying expectations may well depend upon institutional cultural, social, political factors, as per the case of the profound differences between Italian Regions (Franchino and Radaelli, 2011; Salvati and Carlucci, 2015; Caldarelli et al., 2013). On this basis, we argue that the information emphasised in Regional Anticorruption Plans, and the possible heterogeneity among Italian Regions, is not explained by factors such as the regional dimension or the degree of corruption and concussion. On this basis we hypothesise that:

$\mathrm{H} 3$ there is no association between the heterogeneity of the disclosure and the regional dimension.

H4 there is no association between the heterogeneity of the disclosure and the regional degree of corruption and concussion.

\section{Research design}

For the purposes of the study we examined 20 Anti-Corruption Plans prepared for the first time by Italian Regional Governments for the years 20132016 using a meaning-oriented content analysis.

This is a method that has traditionally been applied to the analysis of archival data, focusing on inferring the underlying meanings present in the texts being investigated (Smith and Taffler, 2000). The potential contribution of content analysis is that it can enable researchers to go beyond the text as presented to make valid inferences about hidden or underlying (and possibly unintended meanings) and messages of interest (Weber, 1990). Given that some criticisms have been raised against this method, because of possible subjectivity, a validation procedure was necessary (Adler and Milne, 1998).

The data reported in this paper are based on coding performed by three independent researchers. Following discussion and interpretation of the framework, a coding system was developed after reading an initial sample of 3 Regional Plans. We relied upon the distinction between symbolic and substantive information suggested by Day and Woodward (2004). 
In detail, these authors believe that the symbolic disclosure (the formal one) is essentially documented when a particular aspect - not limited to the improvement of institutional arrangements - is mentioned in the plan but not accompanied by reports that enable an understanding of the different actions in the most wider context of the corporate performance (e.g., the reasons which prompted any changes, the strategic and operating objectives, the impact on results and applications, how to implement the changes or monitoring activities undertaken).

The disclosure is regarded as substantive when at least one of the two following parameters is achieved: existence of detailed explanations of the mechanisms and/or strategies driving actions, and presence of clarification in relation to the actions taken. These aspects are considered important as they lead to a traslucid disclosure that allows the reader to fully comprehend how and why certain dynamics take place within the organisation.

The robustness of the approach used was tested through a measurement of the response-matching level of the codification made on the same documents. Considering the responses of the researchers, taken two by two, the mean values of inter-rater reliability were calculated. $\Pi$ Scott's index is equal to 0.82 , with values included within the interval $0.80-0.88$. Usually, in literature a value of $\pi$ equal to 0.75 is considered a satisfying level of inter-rater reliability. A further analysis of codification coherence, considering at the same time the three researchers' activities, has been verified using the Bhapkar's test. Bhapkar's test checks the marginal homogeneity of all the categories simultaneously. For all the characteristics considered, the statistical test is not significant (considering a threshold 0.1 of I-type test error), and it is possible to conclude that the codification is concordant.

The analysis allowed us to understand the degree of thoroughness of the information provided in relation to the items required by the National AntiCorruption Plan. The dependent variable 'thoroughness' was measured as a latent construct. We examined Regional Plans according to the classification shown in table 1 (www.sidrea.it/disclosure-Anti-Corruption-Plans). In line with the literature (Day and Woodward, 2004), for each disclosure item we attempted to identify if the information was thorough, average, limited, or absent.

After the first step, recognising that the Plan prepared by Trentino Alto Adige often refers to those prepared by the two Autonomous Provinces of Trento and Bolzano (due to the special legal statute of the Region) we removed this document from the initial sample, to avoid any problems relating to outliers values.

Then, we carried out a multiple correspondence analysis (MCA) 
(Benzécri, 1973). This multidimensional analysis is an extension of correspondence analysis in case of more than two qualitative variables. The MCA allows us to create a map of the relations in disclosure practices among the different Italian Regions. The interpretation of the map is based upon proximities among the points, which are projected in a two-dimensional space. Proximities are meaningful only among points from the same set. Unit-points that are closer to each other tend to select the same levels of the nominal variables.

As the factorial solution has been defined, the individuals (i.e. the Regions) have been projected on the maps, to identify their position in respect to the average behaviour. Finally, the independent variables - the regional dimension, and the regional degree of corruption and concussion - were added to the maps to understand their association with the disclosure behaviours.

The independent variables were all continuous and were measured as follows. The regional dimension was measured as the GDP per capita for each Region (Barro, 1997), and as the number of inhabitants. Following Del Monte and Papagni (2007) the regional degree of corruption and concussion was measured as the ratio between the number of crimes per Region and the number of inhabitants. All of these data were taken from the Italian Statistics Institute (ISTAT) website (last update march 2016).

\section{Findings}

The results of the meaning-oriented content analysis (see table 2 in: www.sidrea.it/disclosure-Anti-Corruption-Plans) reveal that the identification of the subjects involved, both internal and external, of their tasks, and their responsibilities, as well as training issues, are highly regarded only by the $30 \%$ of the Regions, while the majority do not put much effort in providing thorough information on this regard. With reference to communication channels and practices to share the content of the plans, the majority of the Regions devote scarce attention to communicate how these processes are designed and implemented. Looking at the disclosure items concerning risk assessment, risk identification, and prevention measures, thoroughness increases but only to a limited extent. On the contrary, Italian Regions appear to neglect in their reports all the issues relating to the monitoring processes and to the coordination with the performance. In this regard it should be noted that despite their importance, these items are greatly overlooked and 
strongly signals that in general Regions tend to provide a symbolic disclosure devoted to formal legitimacy aspirations.

Also, on the basis of previous table 2, we also carried out a hierarchical cluster analysis to identify homogeneous groups of Regions and to better interpret the results (Fig. 1, www.sidrea.it/disclosure-Anti-Corruption-Plans).

The cluster analysis shows that the Regions can be grouped into two clusters, on the basis of the thoroughness of their guidelines. Cluster 1 (Abruzzo, Lazio, Marche, Emilia Romagna, Lombardia, Molise, Friuli, Veneto, Valle d'Aosta) contains the Regions characterised by greater thoroughness of the information, which are located in the centre and in the north of the country. On the other hand, cluster 2 (Basilicata, Calabria, Sardegna, Campania, Liguria, Puglia, Sicilia, Toscana, Trentino) contains Regions that provide less thorough guidelines and are located, in the majority of the cases, in the South of Italy.

In order to provide a clear representation of the heterogeneity of anti-corruption plans in Italy, the second step of the analysis involved a multiplecorrespondences analysis (MCA) (Benzecri, 1973). The MCA is a multidimensional data analysis method used to analyse a set of observations described by different variables which are organized in a matrix (Burt Matrix).

The 12 active variables displayed in previous table 2 were employed to construct the map.

The four independent variables (GDP per capita, number of inhabitants, the ratio between the number of corruption crimes per Region and the number of inhabitants, the ratio between the number of concussion crimes per Region and the number of inhabitants) did not contribute directly to the identification of the factorial solution but were simply projected to help to better describe the phenomenon. The statistics for the independent variables are reported in table 3 (www.sidrea.it/disclosure-Anti-Corruption-Plans).

The interpretation of the MCA results is based upon proximities among points which are projected in a two dimensional space. More specifically, when two observations are close one to another, it means that they have a similar degree of nominal variables.

The MCA identifies two dimensions, i.e. thoroughness of the disclosure on the horizontal axis and heterogeneity of the disclosure items on the vertical axis (see Figure 2: www.sidrea.it/disclosure-Anti-Corruption-Plans). What should be noted is that the black points represent a projection of the Regions, while the white points represent the projection of the disclosure items. The map reveals high dispersion and highlights differences among the settings examined. 
More specifically, moving from the left to the right side of the map (following the horizontal axis) Regions show an increasing level of thoroughness in the disclosure provided in accordance with the NAP requirements. This allow us to signal that Regions such Emilia Romagna and Friuli Venezia Giulia provide a disclosure with a greater degree of thoroughness than Campania and Puglia. Differently, Trentino Alto Adige, Toscana, and Sicilia are featured by common characteristics in terms of both the thoroughness and the types of item addressed.

Moreover, as explained above the vertical distance is a measure of the heterogeneity of the disclosure items provided. Thus, if we move from the top to the bottom side, figure 2 allows us to identify those Regions characterised by similarities in the disclosure items preferred. This reveals, for instance, that Emilia Romagna and Veneto show a similar degree of thoroughness but the distance among them also put into light that they devote attention to different aspects in the information divulged. On the other hand, Liguria and Calabria show a similar degree of overall thoroughness but the vertical distance between them is due to the heterogeneity of the information provided.

Finally, in relation to possible explications for the Regions' behaviours, the independent variables projected on the map allow us to conclude that $\mathrm{H} 1$ and $\mathrm{H} 2$ are confirmed. Indeed, both the independent variables (regional dimension and the degree of corruption and concussion) have a positive relation with the thoroughness of the disclosure. This means that the thoroughness of the disclosure increases when both the regional dimension and the degree of corruption and concussion increase. These findings allow us to state that in the Regions with larger dimensions and with a greater number of corruption crimes there is greater attention to disclosure creation and the Anti-corruption plan presents greater thoroughness.

These findings are aligned with those of D'Onza et al. (2016) who signal that larger Regions provide a higher number of Anti-corruption disclosure items.

Likewise, $\mathrm{H} 3$ and $\mathrm{H} 4$ are confirmed as the heterogeneity between Regions in not associated with the regional dimension and the degree of corruption and concussion. This means that the heterogeneity of Anti-corruption plans does not have any strong relation with the regional dimension or the Regional GDP. This means that the attention provided to the disclosure creation depends mainly to the number of corruption and concussion crimes than to the number of inhabitants or regional GDP. 


\section{Discussion and conclusions}

The results highlight interesting issues that deserve further explanations. A first feature concerns disclosure items. The already cited high heterogeneity within the national context is even more problematic if we consider that the thoroughness of the information on the whole prevention process is generally scarce. Indeed, only in a few cases the disclosure items listed in table 1 receive the necessary attention. On the contrary, a compartmentalised approach to disclosure is evident in the majority of the Regions, for which it is highly challenging to catch a general picture of the phenomena observed. In particular, the neglected issues relating to monitoring and coordination represent a red flag of attempts to reach formal compliance rather than a substantial effort to achieve greater accountability.

Focusing on the results of the MCA, it is possible to identify two opposite situations. The Regions placed in the right side of the map provide thorough and substantive disclosure to satisfy broader accountability expectations. One could argue that these Regions have experienced an evolutionary change, prompted by new regulatory attempts, but then proactively internalised in its practices. This led to the progressive creation of a shared accountability and control culture. On the contrary, the Regions placed in left side of the map provide a disclosure oriented towards formal compliance for legitimacy purposes. It is possible to argue that these settings have experienced a change inevitably internalised within the organisation, given the institutional and regulatory pressures, but that has not yet influenced their cultural dimension. It is therefore not possible to find in these Regions an accepted and shared control culture guided by accountability aims in relation to corruption prevention.

In addition, in line with D'Onza et al. (2016), the research further reinforces the view that anticorruption disclosure on the one hand, is strictly related with the public organization dimension, and on the other hand, it may well be used to restore trust after illegal events and to prevent any chances of reputational damage (in this latter regard see also Suchman, 1995; O'Donovan, 2002; Lindblom, 1994; Dowling and Pfeffer, 1975). However, our study goes even further because it not only considers disclosure quantity, but encompasses the questions relating to the thoroughness of the above-cited disclosure, allowing us to consider any implications relating to the heterogeneity of the information, which as stated is not associated with the variables considered.

In this regard, it is worth noting that although this study reveals growing attention by the Regions to the improvement of the corruption prevention 
systems, and thus towards the development of a culture of control, it also highlights that the guidelines for the conduct of management action and the parameters of the evaluation processes are very heterogeneous. Such heterogeneity, together with the political influence allowed by law (see also Caldarelli et al., 2013), does not allow full comparability. It is therefore reasonable to assume that a risk of misalignment might exist, as the Regions reluctant to changes could strive to maintain a state of inertia, rather than converging gradually towards the more advanced model of the other ones. Indeed, the different reactions of the Regions shown above may be largely attributable to factors not currently employed in the analysis but actually crucial, such as the characteristics of Regional governance (Caldarelli et al., 2013) and the full comprehension of the new regulation (Spanò et al., 2016). In line with Dunphy and Doug (1988) and Caldarelli et al. (2013), evolutionary changes leading to more thorough disclosure could have been favoured where the Regions have benefited from an already promising background in terms of the management resources available, the collaborative approaches and the presence of shared values between individuals, as well as in the presence of propensity towards such collaborative approaches.

Before concluding, several caveats need to be considered. The research could suffer some limitations relating to the choice of focusing only on the Regional Anticorruption Plans, rather than considering also other operational documents. The choice is driven by the desire to analyse the regional dimension and the reaction of the Regions to regulatory and institutional pressures, rather than the process in itself, and its implications. In fact, in our opinion, the latter theme is very important, and deserves more attention so as to observe the evolution of the prevention systems over time, by concentrating on a comparative case study. However, in this sense, these results, providing an interesting overview of the degree of implementation of the policies promoted by the on-going reforms, represent a good starting point as they are helpful in recognizing which Regions are 'lagging behind', to select the case studies to analyse in depth. Moreover, the paper suffers a limitation relating to the measurement of the independent variables, above all with reference to the degree of corruption and concussion of the territory. In fact, given the legal implications of current regulation the number of judgements captures only a small portion of the phenomenon. A possible alternative could have been the reliance on the degree of perceived corruption, but again this suffers limits, especially in terms of high subjectivity and therefore we decided to eliminate this option.

Furthermore, the research has practical and policy relevance. Indeed, in the light of the foregoing, the research suggests that it may be worthwhile 
promoting, at central level, the adoption of ex ante measures to ensure the proper, formalised and shared implementation of corruption prevention systems in each Region, in addition to the ex post control operated by the Anticorruption National Authority. Yet, the results of the analysis shed light on the type of change that regulation has fostered over the last years, especially focusing on the capability of regulators to guide Regions towards the provision of more useful disclosure through the introduction of new and increasingly detailed legal requirements. The findings allowed us to detect the existence of any limitations of the complex system of corruption prevention disclosure regulation, and provide a basis for some critical thoughts emphasizing that the weaknesses of corruption prevention disclosure do not represent a question of compliance but might reflect the inefficiencies of regulation per se.

\section{References}

Adler R., Milne M. (1998), Challenges of learner-centred education: Examine reasons for a lack of interest in this area, Chartered Accountants Journal of New Zealand, 77(1), 1219.

Allini A., Caldarelli A., Spanò R., Zampella A. (2019), Legitimating efforts in Performance Plans. Evidences on the thoroughness of disclosure in the Italian Higher Education setting, Management Control, 1, 143-168. Doi: 10.3280/MACO2019-001007.

Anessi Pessina E., Steccolini I. (2005), Evolutions and Limits of New Public Management Inspired Budgeting Practices in Italian Local Governments, Public Budgeting \& Finance, 25(2), 1-14.

Ashforth B.E., Gibbs B.W. (1990), The double-edge of organizational legitimation, Organization Science, 1(1), 177-194.

Barro R.J. (1997), Determinants of Economic Growth: A Cross-Country Empirical Study, Cambridge, MA, MIT Press.

Benavides A. (2006), Transparency and public administration in Mexico: how the enactment of a law is changing culture, Journal of Public Affair Education, 12(4), 461-477.

Benzécri, J. P. (1973). The data analysis: Volume I: Taxonomy. Volume 2: Analysis of correspondence, Paris, Dunod.

Brown N., Deegan C. (1998), The Public Disclosure of Environmental Performance Information-a Dual Test of Media Agenda Setting Theory and Legitimacy Theory, Accounting \& Business Research, 29(1), 21-42.

Caiden G.E. (1988), Toward a General Theory of Official Corruption, Asian Journal of Public Administration, 10(1).

Cardarelli A., Maffei M., Spanò R. (2012), I sistemi di valutazione della performance dei Direttori Generali come processo trasformazionale. Un'analisi empirica dei Servizi Regionali Italiani, Management Control, 3, 37-62. Doi: 10.3280/MACO2012-003003.

Caldarelli A., Fiondella C., Maffei M., Spanò R., Aria M. (2013). CEO performance evaluation systems: empirical findings from the Italian health service. Public Money \& Management, 33(5), 369-376. 
Cho C.H., Patten D.M. (2007), The role of environmental disclosures as tools of legitimacy: A research note. Accounting, Organizations and Society, 32(7-8), 639-647.

D’Onza G., Brotini F., Zarone V. (2015), Le determinanti della risk disclosure nei piani anticorruzione: uno studio sulle amministrazioni pubbliche italiane, Azienda Pubblica, 1, 3362.

D’Onza G., Brotini F., Zarone V. (2016), Disclosure on Measures to Prevent Corruption Risks: A Study of Italian Local Governments, International journal of public administration, 40(7), 612-624.

Day R., Woodward T. (2004), Disclosure of information about employees in the Directors' report of UK published financial statements: substantive or symbolic?, Accounting Forum, 28(1), 43-59.

Deegan C. (2002), The legitimising effect of social and environmental disclosures: A theoretical foundation, Accounting, Auditing and Accountability Journal, 15(3), 282-311.

Deegan C., Rankin M. (1997), The Materiality of Environmental Information to Users of Annual Reports, Accounting, Auditing \& Accountability Journal, 10(4), 562-576.

Deegan C., Rankin M., Tobin J. (2002), An Examination of the Corporate Social and Environmental Disclosures of BHP from 1983-1997: A Test of Legitimacy Theory. Accounting, Auditing \& Accountability Journal, 15(3), 312-343.

Del Monte A., Papagni E. (2007), The determinants of corruption in Italy: Regional panel data analysis, European Journal of Political Economy, 23(2), 379-396.

Dowling J., Pfeffer J. (1975), Organizational legitimacy: Social values and organizational behaviour, Pacific Sociological Review, 18(1), 122-136.

Dunphy D.C., Doug A.S. (1988), Transformational and Coercive Strategies for Planned Organizational Change: Beyond the O.D. Model, Organization studies, 9(3), 317-334.

Edkins A. (2009), Risk disclosure and re-establishing legitimacy in the event of a crisis - Did Northern Rock use risk disclosure to repair legitimacy after their 2007 collapse? Department of Management Studies, University of York.

Elzahar H., Hussainey K. (2012), Determinants of narrative risk disclosures in UK interim reports, The Journal of Risk Finance, 13(2), 133-147.

Fadda I., Paglietti P. (2016), La lotta alla corruzione: più controlli interni e meno adempimenti, Azienda Pubblica, 1, 77-92.

Fearon G. (2009), Economics of public good provision: auditing, outsourcing, and bribery, Can Journal Econ/Rev Can d'écon, 42(3), 997-1022.

Fiorino N., Galli E. (2013), La corruzione in Italia. Un'analisi economica, Bologna, il Mulino.

Gilman S.C., Stout J. (2008), Assessment strategies and practices for integrity and anti-corruption measures: a comparative overview, in B. Head, A.J. Brown, C. Connors (Eds.), Promoting integrity: evaluating and improving public institutions, Ashgate, Surrey, pp. 243-284.

Gray R., Bebbington J. (2000), Environmental accounting, managerialism and sustainability: is the planet safe in the hands of business accounting?, Advances in environmental accounting \& management, 1(1).

Gray R.H., Owen D.L., Adams C. (1996), Accounting and accountability: Changes and challenges in corporate social and environmental reporting, London, Prentice Hall.

Hawkins T., Gravier M., Powley E. (2011), Public vs. private sector procurement ethics and strategy: what each sector can learn from the other, Journal of Business Ethics, 103(4), 567-586.

Hinna L., Marcantoni M. (2013), Corruzione. La tassa più iniqua, Roma, Donzelli Editore. 
Hogner R.H. (1982). Corporate social reporting: Eight decades of development at US Steel, Research in Corporate Performance and Policy, 4(2), 243-250.

Kartal M. (2014). Accounting for the bad apples: the EU's impact on national corruption before and after accession, Journal of European Public Policy, 21(6), 941-959.

Lindblom C.K. (1994), The Implications of Organizational Legitimacy for Corporate Social Performance and Disclosure, Critical Perspectives on Accounting Conference, New York.

Lisciandra M., Millemaci E. (2016), The economic effect of corruption in Italy: a regional panel analysis, Regional Studies, 1-12.

Magtulis P.P., Poquiz J.L. (2016), Big Government, Big Corruption? Examining the Relationship between Government Size and Public Corruption in the Philippines. International Journal of Public Administration, 40(11), 954-967.

Marchi L. (2011), Integrazione pubblico-privato su metodologie e strumenti di controllo gestionale, Management Control, 2, 5-8. Doi: 10.3280/MACO2011-002001.

McCampbell A.S., Rood T.L. (1997), Ethics in government: a survey of misuse of position for personal gain and its implications for developing acquisition strategy, Journal of Business Ethics, 16(11), 1107-1116.

Moerman L., Van Der Laan S. (2005), Social reporting in the tobacco industry: all smoke and mirrors?. Accounting, Auditing \& Accountability Journal, 18(3), 374-389.

Morris M., Schindehutte M., Allen J. (2005), The entrepreneur's business model: toward a unified perspective, Journal of business research, 58(6), 726-735.

Mulgan R., (2000). “Accountability": An Ever Expanding Concept?, Public Administration, $78(1), 555$.

Neu D., Everett J., Rahaman A.S., Martinez D. (2013), Accounting and networks of corruption. Accounting, Organizations and Society, 38(6-7), 505-524.

O'Donovan, G. (2002), Environmental Disclosures in the Annual Report: Extending the Applicability and Predictive Power of Legitimacy Theory, Accounting, Auditing and Accountability, 15(3), 344-371.

Ongaro E., Valotti G. (2008), Public management reform in Italy: explaining the implementation gap, International Journal of Public Sector Management, 21(2), 174-204.

Pavan A., Fadda I. (2013), I controlli interni per il buon andamento del settore pubblico Italiano, Azienda Pubblica, 4, 431-449.

Pavan A., Reginato E., Fadda I., Paglietti P., Landis C. (2013), Il sistema di controllo interno negli Enti Locali Italiani, In L. Anselmi et al. (a cura di), Il declino del sistema dei controlli manageriali nelle pubbliche amministrazioni. Dal federalismo ai costi standard, Milano, FrancoAngeli.

Pollit C. (2006), Changing european states, changing public administration: antistatist reforms and new administrative directions. Comparative public administration: the essential readings, 777.

Radaelli C., Franchino F. (2004), Analysing political change in Italy, Journal of European Public Policy, 11(6), 941-953.

Rose-Ackerman S. (1999), Corruption and government: Causes, consequences, and reform. Cambridge university press.

Salvati L., Carlucci M. (2016), Patterns of sprawl: The socioeconomic and territorial profile of dispersed urban areas in Italy, Regional Studies, 50(8), 1346-1359.

Sevüktekin M., Nargeleçekenler M., Giray F. (2010), A Cross-Country Comparison of Corruption and Public Expenditures: A Panel Data Approach, International Journal of Public Administration, 33(3), 140-150.

Shim D.C., Eom T.H. (2008), E-government and anti-corruption: Empirical analysis of international data, International Journal of Public Administration, 31(3), 298-316. 
Siame F. (2002), Contributions and challenges in the fight against corruption - an auditor general's perspective, International Journal of Governance and Auditing, 29(4), 7-9.

Smith M., Taffler R.J. (2000), The chairman's statement-A content analysis of discretionary narrative disclosures, Accounting, Auditing \& Accountability Journal, 13(5), 624-647.

Søreide T. (2002), Corruption in public procurement: causes, consequences and cures, Bergen, Chr. Michelsen Institute.

Søreide T. (2006), Is It Wrong to Rank? A Critical Assessment of Corruption Indices. CMI Working Paper.

Spanò R., DI Paola N., Caldarelli A., Vona R. (2016). Accountants' hybridization and juridification: a critical reflection on the fight against organized crime, Public Money \& Management, (Forthcoming: 10.1080/09540962.2016.1190208).

Stolfi F. (2008), The Europeanization of Italy's budget institutions in the1990s, Journal of European Public Policy, 15(4), 550-566.

Strombom D., (1998). Corruption in Procurement, Economic Perspectives, 3(5), Electronic journals of the US Information Agency, -- http://usinfo.state.gov/journals/ites/1198/ijee/strombom.htm.

Suchman M. C. (1995). Managing Legitimacy: Strategic and Institutional Approaches, Academy of Management Journal, 20(3), 571-610.

Weber R. P. (1990), Basic content analysis (No. 49), Sage. 